\title{
A proteomic study of the aortic media in human thoracic aortic dissection: Implication for oxidative stress
}

\author{
Mingfang Liao, MD, PhD, ${ }^{a}$ Zhaoyang Liu, $\mathrm{PhD},{ }^{c}$ Junmin Bao, MD, ${ }^{a}$ Zhiqing Zhao, MD, a Jianwen $\mathrm{Hu}, \mathrm{PhD},{ }^{c}$ \\ Xiang Feng, MD, ${ }^{\text {a }}$ Rui Feng, MD, ${ }^{\text {a }}$ Qingsheng Lu, MD, ${ }^{\text {a }}$ Zhijun Mei, MD, ${ }^{\text {a }}$ Yanling Liu, MS, ${ }^{\text {b }}$ Qingyu Wu, MD, PhD, ${ }^{d}$ and \\ Zaiping Jing, $\mathrm{MD}^{\mathrm{a}}$
}

Supplemental material is available online.
From the Department of Vascular Surgery ${ }^{\mathrm{a}}$ and Cardiothoracic Surgery, ${ }^{\mathrm{b}}$ Changhai Hospital, Second Military Medical University, and Research Center for Proteome Analysis, ${ }^{\mathrm{c}}$ Institute of Biochemistry and Cell Biology, Chinese Academy of Sciences, Shanghai, China; and the Departments of Molecular Cardiology and Nephrology, ${ }^{\mathrm{d}}$ Cleveland Clinic, Ohio.

This work was supported by the National Natural Science Foundation of China (30600599).

Received for publication April 24, 2007; revisions received Oct 29, 2007; accepted for publication Nov 15, 2007.

Address for reprints: Zaiping Jing, MD, Department of Vascular Surgery, Changhai Hospital, Second Military Medical University, No. 174 Changhai Rd, Shanghai, 200433 China (E-mail: sh.vascular@ yahoo.com.cn).

J Thorac Cardiovasc Surg 2008;136:65-72 0022-5223/\$34.00

Copyright $\odot 2008$ by The American Association for Thoracic Surgery

doi:10.1016/j.jtcvs.2007.11.017
Objective: The aortic media lesion is a key pathologic feature in thoracic aortic dissection. To identify key proteins in aortic media lesions that may contribute to its pathogenesis, we performed proteomic studies to find differentially expressed proteins in the media from diseased and normal thoracic aorta.

Methods: Ascending aortic segments were obtained from patients with thoracic aortic dissection $(n=8)$ and age-matched normal donors $(n=6)$. The differentially expressed proteins of their media tissues were analyzed by 2-dimensional electrophoresis and mass spectrometry, and verified by Western blotting. Oxidative stress was measured by functional assays in a larger sample size (15 patients and 10 controls).

Results: Image analysis of the protein profiles from 2-dimensional gels revealed 126 differentially expressed proteins, of which 26 were identified by mass spectrometry. Among them, extracellular superoxide dismutase, an enzyme involved in oxidative stress, was selected for further studies. Western blotting showed that extracellular superoxide dismutase expression was more than 50\% lower in patient samples than in controls $(P<.001)$. Superoxide dismutase activity was consistently decreased $(P<.001)$ and lipid peroxidation was increased $(P=.019)$ in patient media homogenates compared with that in controls.

Conclusion: Our results indicate that protein expression profiles in the aortic media from thoracic aortic dissection differ significantly from that of controls, which may provide important insights into the disease mechanisms. This study also suggests that increased oxidative stress may play an important role in the disease.

$\mathrm{T}$ horacic aortic dissection (TAD) is one of the most catastrophic aortic diseases. It is characterized by the separation of thoracic aortic wall layers by extraluminal blood that usually enters the vessel wall via an intimal tear. ${ }^{1}$ Mechanisms weakening the aortic wall can induce aortic dilatation, aneurysm formation, and even rupture. ${ }^{1}$ The development of endovascular techniques has improved the diagnosis and treatment of TAD. To date, however, the mortality associated with aortic rupture remains high. Many patients with TAD die of aortic rupture before reaching hospitals. Thus, it is important to develop strategies to prevent this catastrophic disease. Many studies have been performed to understand the pathogenesis of TAD. Most of them focus on the genetic heterogeneity, clinical pathology, and hemodynamics of $\mathrm{TAD},{ }^{2,3}$ which have provided important insights into the disease mechanisms.

Proteomics using 2-dimensional gel electrophoresis (2-DE) and mass spectrometry $(\mathrm{MS})^{4}$ has recently been applied to study cancer ${ }^{5}$ and cardiovascular diseases. ${ }^{6}$ Comparative proteomics (ie, diseased vs normal tissue) has been used to study atherosclerosis, including coronary and carotid atherosclerotic plaques and the smooth muscle cell (SMC) secretome. ${ }^{7-9}$ McGregor and colleagues ${ }^{10}$ presented a protein profile map of human saphenous vein medial smooth muscle by 2-DE and identified 129 differentially expressed proteins. To date, comparative proteomic 

Abbreviations and Acronyms
2-DE $\quad=2$-dimensional gel electrophoresis
EC-SOD $=$ extracellular superoxide dismutase
HSP $=$ heat shock protein
MDA $=$ malondialdehyde
MS $=$ mass spectrometry
NA $=$ normal thoracic aorta
SMC $=$ smooth muscle cell
SOD = superoxide dismutase
TAD $=$ thoracic aortic dissection

profiles of the aorta from patients with TAD have not been reported. Such data will help to identify key proteins involved in TAD and elucidate their functions in the disease.

In this study, we initiated a proteomic analysis of aortic tissues from patients with TAD. Because cellular composition in the aortic wall is heterogeneous, a proteomic analysis of the entire aortic wall will be technically challenging. For instance, intimal atherosclerotic lesions are present in most aortas from patients with TAD, whereas such lesions are less common in normal thoracic aortas (NAs), making comparative studies difficult. To circumvent this problem, we focused on the aortic media, which is more homogenous in its cellular composition.

By using 2-DE and MS, we produced a first map of human thoracic aortic media protein profiles and analyzed differentially expressed proteins between the TAD and NA groups. A total of 126 differentially expressed proteins were identified, of which 26 proteins were analyzed by MS. One of them, extracellular superoxide dismutase (EC-SOD), was selected for in-depth studies.

\section{Materials and Methods Proteomic Analysis}

Aortic samples. The study was approved by the ethics committee of our hospital. All patients gave informed consent. Ascending aorta segments were collected from patients with TAD undergoing surgical repair ( 8 male, mean age: $47.5 \pm 6.9$ years). NAs were from organ donors ( 6 male, mean age: $39.5 \pm 7.2$ years). No significant difference in age was found between the TAD and NA groups $(P>.05)$. A detailed description of aortic samples is supplemented online (Table E1). All samples used in this study were prepared in parallel on the basis of a published method. ${ }^{10}$ Briefly, media tissues were cut into small pieces and stored at $-80^{\circ} \mathrm{C}$ until protein extraction. Some tissues were preserved by paraffin imbedding for immunohistochemistry validation using monoclonal antibody specific for SMC marker (alpha smooth muscle actin) and endothelial cell marker (CD-31). Hematoxylin and eosin and Victoria blue staining for elastic and collagen fibers were done for all tissue samples using standard procedures.

Preparation of tissue samples. Tissue samples were prepared according to the methods described by Weekes and colleagues ${ }^{11}$ and McGregor and colleagues. ${ }^{10}$ Frozen aortic tissues $(\sim 10 \mathrm{mg})$ were ground using a grinding tube with a matching pestle in an iced bath. Resulting powders were homogenized in $100 \mu \mathrm{L}$ lysis buffer $(9 \mathrm{~mol} / \mathrm{L}$ urea, 4\% CHAPS, $65 \mathrm{mmol} / \mathrm{L}$ dithiothreitol, and $1 \mathrm{mmol} / \mathrm{L}$ phenylmethylsulfonyl fluoride) at $4{ }^{\circ} \mathrm{C}$ for 5 minutes and then centrifuged at $4^{\circ} \mathrm{C}$ at $14,000 \mathrm{rpm}$ for 1 hour. The supernatant was collected, and protein concentrations were determined using a modified method described by Bradford. ${ }^{12}$ Supernatant samples were divided into $50-\mu \mathrm{L}$ aliquots and stored at $-80^{\circ} \mathrm{C}$.

Two-dimensional gel electrophoresis. 2-DE was performed according to the methods described by Weekes and colleagues ${ }^{11}$ and $\mathrm{Yu}$ and colleagues. ${ }^{13}$ The details of these methods are provided in supplemented documents online (Appendix E1).

Image analysis. Images of stained gels were acquired using a scanner (GS-800 densitometry, Bio-Rad, Richmond, Calif) and analyzed with PDQuest 7.2.0 2-dimensional image analysis software (Bio-Rad). ${ }^{14}$ Spot densities were determined following normalization based on total spot volumes on the gel. Protein spots from different gels were matched. Protein spots that had significant changes in densities $(P<.05)$ in a consistent direction (increase or decrease) were considered to be different.

Mass spectrometry. In-gel tryptic digestion and MS identification were carried out according to published methods. ${ }^{13,14}$ The peptide mass spectrum for each sample was obtained with matrixassisted laser desorption/ionization time-of-flight/time-of-flight MS (Bruker, Daltonics Autoflex Billerica, MA). The obtained peptide masses were searched against the National Center for Biotechnology Information protein database using the Mascot program (Matrix Science, Boston, Mass).

\section{Western Blotting}

Western blotting analysis of aortic protein extracts was performed to validate EC-SOD expression with standard procedures. A rabbit anti-EC-SOD polyclonal antibody (Alpha Diagnostic International, San Antonio, TX), and horseradish peroxidase-labeled secondary antibody (Santa Cruz Biochemicals, Santa Cruz, Calif) were used in these studies.

\section{Assays for Oxidative Stress}

Superoxide dismutase (SOD) activity, lipid peroxidation, and catalase activity in aortic media tissues were determined. In addition to the samples used in 2-DE, we included additional samples from other patients to increase sample size and to confirm our findings in independent patients. There was no significant difference in age between the TAD group (13 men and 2 women, mean age: 47.4 \pm 9.2 years) and NA group (9 men and 1 woman, mean age: $40.9 \pm 6.7$ years $)(P>.05)$. A detailed description of these samples is supplemented online (Table E1). SOD activity in aortic media homogenates was assayed on the basis of a published method that measures the inhibitory rate of xanthine oxidase-mediated reduction of cytochrome $c(\mathrm{pH} 7.4) .{ }^{15}$ Cyanide $(3 \mathrm{mmol} / \mathrm{L})$ was used to distinguish between the cyanide-sensitive isozymes $\mathrm{Cu} / \mathrm{Zn}-\mathrm{SOD}$ and EC-SOD from the cyanide-resistant manganeseSOD. Lipid peroxidation was assayed by measuring the levels of malondialdehyde (MDA) reacted with thiobarbituric acid at 535 nm. ${ }^{16}$ MDA concentrations were expressed as nanomoles per milliliter. Catalase activity was determined by monitoring the breakdown of hydrogen peroxide catalyzed by the catalase enzyme, ${ }^{17}$ and the results were expressed as units per milligram of protein. 


\section{Statistical Analysis}

Statistical analyses were performed using the Statistical Package for the Social Sciences 15.0 (SPSS Inc, Chicago, IL.). Continuous and categoric variables were compared by $t$ test and chi-square/Fisher exact test, respectively. Descriptions of continuous variables were presented as mean \pm standard deviation.

\section{Results}

\section{Histopathology of Thoracic Aortic Dissection}

The ascending aortas from patients with TAD were enlarged and dissected. In most samples examined, large amounts of blood clots were found in false lumens (Figure 1, $A$ ). Microscopic examination of hematoxylin and eosin- and Victoria blue-stained tissues (Figure 1, $B$ and $C$ ) showed that the dissection spread along the laminate of the media between the middle and outer third layers. The aortic wall specimen had elastic fiber loss and fragmentation in the media. Medial tissue identity was confirmed by positive immunostaining of an anti-alpha smooth muscle actin antibody (Figure 1,D) and negative staining of an anti-CD31 antibody (data not shown).

\section{Differential Protein Expression between Thoracic Aortic Dissection and Normal Thoracic Arteries}

Protein profiles were generated by 2-DE. The match rate for protein spots in the same group was $86.7 \% \pm 7.1 \%$ in the NA group and $82.1 \% \pm 7.5 \%$ in the TAD group, indicating a good reproducibility under our experimental conditions. The overall 2-DE profiles of the aortic media from the TAD and NA samples were similar (Figure 2, $A$ and $B$ ).
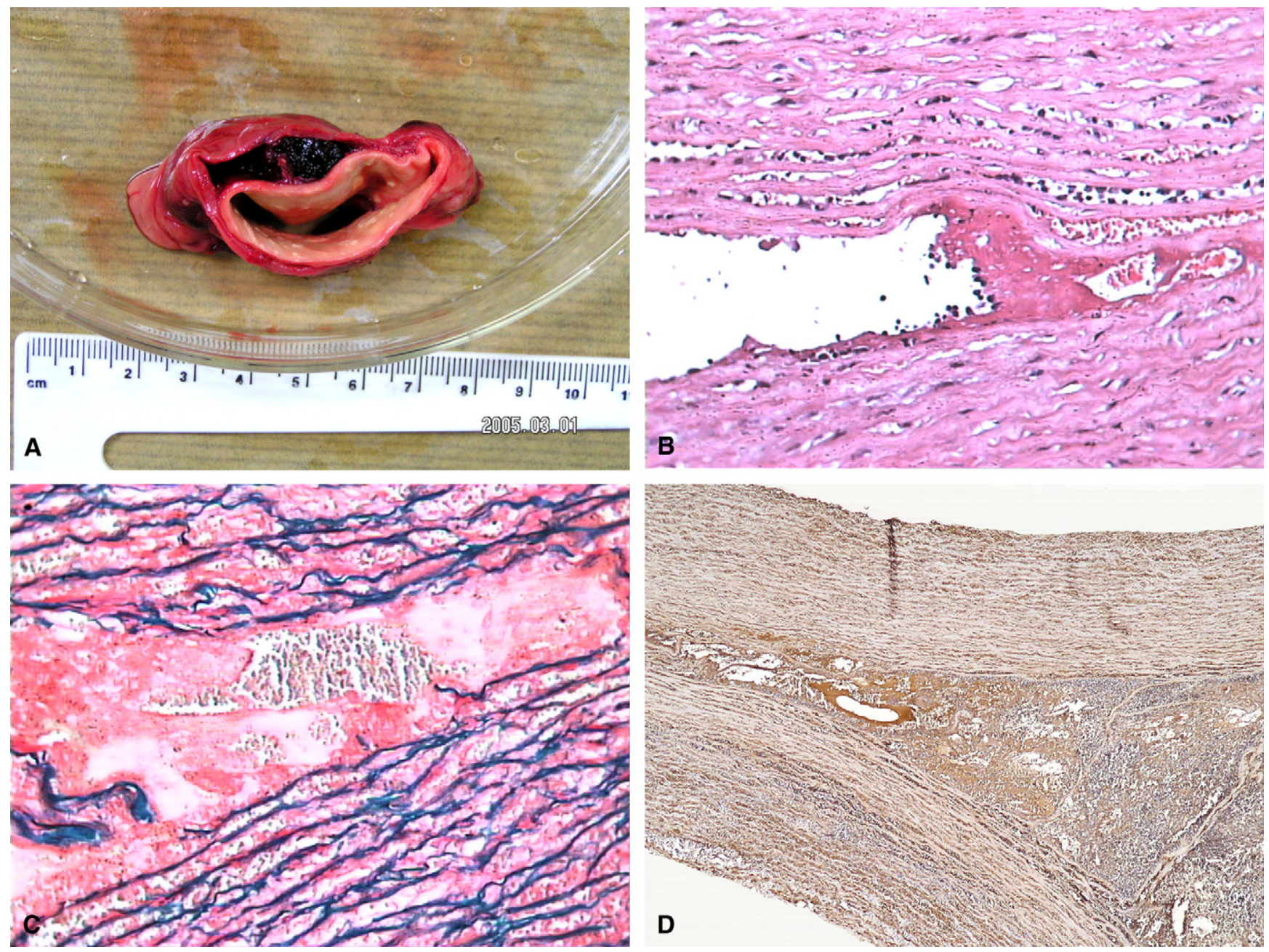

Figure 1. Histopathology of TAD. An image of an ascending aorta from a patient with TAD showing an enlarged and dissected aorta with large amounts of blood clots in the false lumen (A). Hematoxylin and eosin staining of TAD aortic tissue showing the dissected layer in the middle media (B). Fragmentation and rigidity of elastic fiber (blue) in TAD by Victoria blue staining (C). Verification of aortic media by immunostaining of alpha smooth muscle actin (brown) in the media (D). 


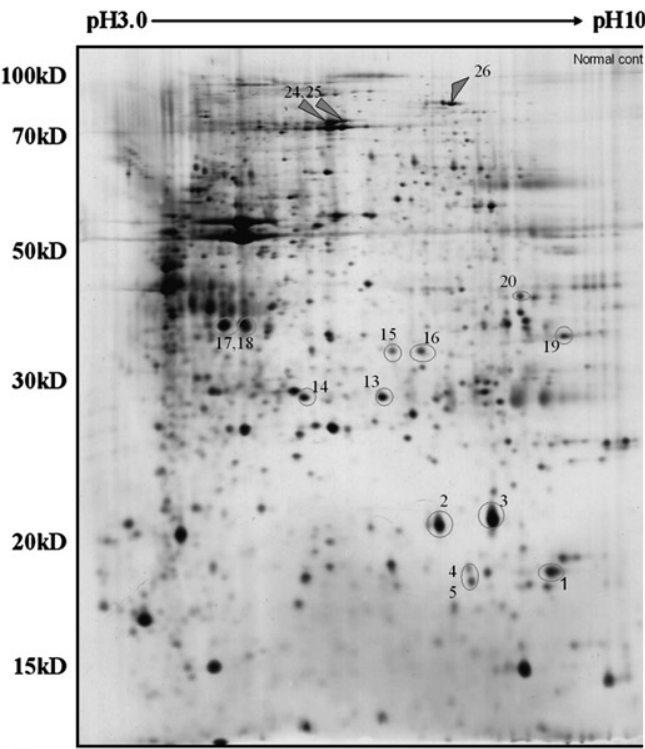

A

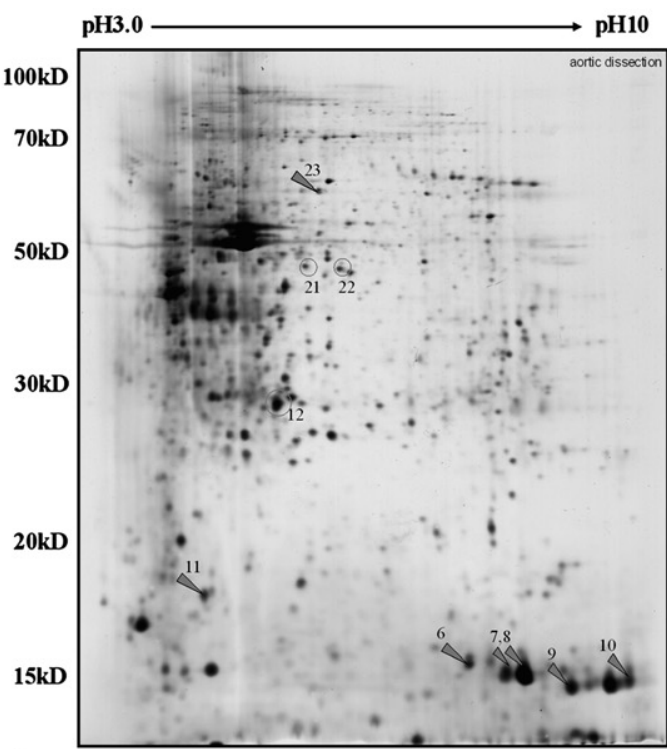

B

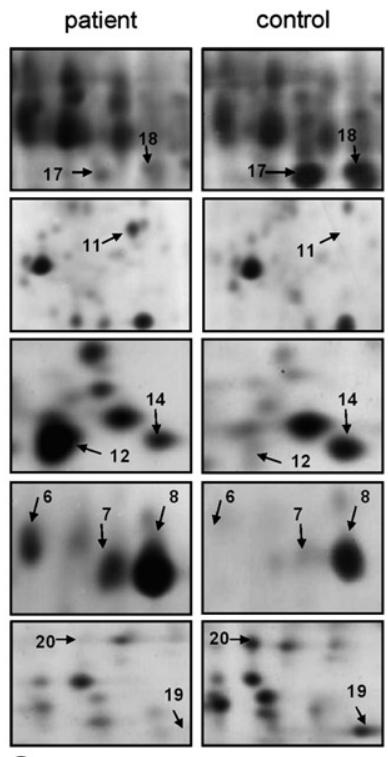

C

Figure 2. 2-DE images of protein profiles of the aortic media. Representative 2-DE images of aortic media protein from a normal control (A) and patient with TAD (B). Protein spots identified by MS were marked with numbers. Enlarged pictures of silver-stained gels highlight the significant differences between samples from patients and controls (C).

Analysis using PDQuest software showed that the total numbers of effective spots in the 2-DE gels were $2123.3 \pm$ 366.8 for the NA group and $2049.5 \pm 403.7$ for the TAD group $(P>.05)$.

By gel matching, 126 differentially expressed protein spots $(P<.05)$ were found between the TAD and NA groups. Twenty-six spots with clear and relatively high expression, scattering locations, and significantly differential expression (most of them $>5$-fold) between the 2 groups were selected for MS identification. These spots may be used as markers for future 2-DE studies. Proteins identified by MS were marked with numbers (Figure 2) and listed in Table 1. Significant differences are highlighted in the enlarged pictures of silver-stained gels (Figure 2, $C$ ). The peptide sequences identified using matrix-assisted laser desorption/ionization time-of-flight/time-of-flight-MS are listed in Table E2. Peptide mass fingerprinting and the tandem mass spectrophotometry spectrum of a representative spot (number 15) are shown in Figure 3.

As shown in Table 1, several cytoskeletal proteins, such as smooth muscle 22-alpha, destrin, alpha-actinin-2-associated LIM protein, and skeletal muscle LIM-protein FHL1, were identified. Other proteins, including EC-SOD, osteoglycin, and heat shock protein (HSP) 27, were found to have decreased expression levels in TAD samples. Other identified proteins included transferrin, hemoglobin chain, fibrin, and serum albumin, some of which may be from residual blood clots in the TAD tissues.

\section{Western Blotting Verification of Extracellular Superoxide Dismutase Expression}

Among the differentially expressed proteins identified, one protein, EC-SOD, is of particular interest because of its role in oxidative stress. We used Western blotting to verify its expression in the tissue samples used in the 2-DE experiments. EC-SOD protein was found in samples from both NA and TAD groups (Figure 4, A). The level of protein expression was significantly lower in the TAD group than in the NA group $(0.43 \pm 0.04$ vs $1.01 \pm 0.03$ relative amount of protein, respectively; $P<.001$ ) (Figure $4, B$ ).

\section{Oxidative Stress Increases in Thoracic Aortic Dissection}

EC-SOD is an important antioxidative enzyme in the vessel wall. The reduced EC-SOD expression level suggests an impaired antioxidative mechanism in the aortic wall in patients with TAD. We next examined oxidative stress markers by functional assays in a larger sample size. Consistently, the level of MDA in aortic media homogenates was significantly increased in the TAD group $(\mathrm{n}=15)$ compared with that in the NA group $(\mathrm{n}=10)(2.33 \pm 0.31 \mathrm{nmol} / \mathrm{mL}$ vs $1.30 \pm 0.18$ $\mathrm{nmol} / \mathrm{mL}$, respectively; $P=.019$ ) (Figure 5, $A$ ). No significant differences in catalase activity and manganese-SOD activity were found between the 2 groups $(P>.05$, Figure $5, B$ and $C$ ). Total SOD activity was lower in aortic media homogenates from the TAD group than in the NA group (4.15 \pm 0.24 vs $6.56 \pm 0.29 \mathrm{U} / \mathrm{mg}$, respectively; $P<.001)$. 
TABLE 1. Differentially expressed proteins between aortic medias of thoracic aortic dissection and normal controls identified by mass spectrometry

\begin{tabular}{|c|c|c|c|c|c|}
\hline $\mathbf{N}$ & Protein identity & $\begin{array}{c}\text { NCBI } \\
\text { entry No. }\end{array}$ & $\begin{array}{c}\text { Calculated } \\
\text { pl/MM (kDa) }\end{array}$ & $\begin{array}{c}\text { Observed } \\
\text { pl/MM (kDa) }\end{array}$ & $\begin{array}{c}\text { Sequence } \\
\text { coverage/mascot score }\end{array}$ \\
\hline 1 & Destrin (actin depolymerizing factor) & gi|55661046 & $8.84 / 15.7$ & $8.15 / 17.8$ & $17 / 126^{*}$ \\
\hline 2 & Smooth muscle 22-alpha/transgelin & gi|62205326 & $8.87 / 22.6$ & $6.78 / 20.8$ & $59 / 145$ \\
\hline 3 & Smooth muscle 22-alpha/transgelin & gi| 179032 & $8.78 / 22.6$ & $7.15 / 21.7$ & $19 / 114^{*}$ \\
\hline 4 & Smooth muscle 22-alpha/transgelin & gi|62205326 & $8.87 / 22.6$ & $7.08 / 18.5$ & $43 / 75$ \\
\hline 5 & Smooth muscle 22-alpha/transgelin & gi|179032 & $8.78 / 22.6$ & 7.09/17.8 & $8 / 60^{*}$ \\
\hline 6 & Chain $A$, domain 3 from human serum albumin & gi|71042087 & $8.22 / 23.3$ & $7.02 / 16.3$ & $24 / 76$ \\
\hline 7 & Chain $\mathrm{D}$, hemoglobin (deoxy) mutant & gi|999567 & $6.70 / 15.9$ & $7.13 / 15.9$ & $75 / 148$ \\
\hline 8 & Chain $\mathrm{D}$, hemoglobin (deoxy) mutant & gi|999567 & $6.70 / 15.9$ & $7.17 / 15.9$ & $75 / 147$ \\
\hline 9 & Chain $\mathrm{C}$, hemoglobin thionville alpha chain mutant & gi|493852 & $7.82 / 15.4$ & $8.25 / 15.1$ & $21 / 94^{*}$ \\
\hline 10 & Chain $\mathrm{C}$, hemoglobin thionville alpha chain mutant & gi|493852 & $7.82 / 15.4$ & $8.87 / 15.8$ & $21 / 144^{*}$ \\
\hline 11 & Actin, alpha 2, smooth muscle, aorta & gi|55957587 & $5.31 / 16.9$ & $4.98 / 17.7$ & $26 / 117^{*}$ \\
\hline 12 & Alpha actin & gi| 178027 & $5.23 / 42.5$ & $5.26 / 31.5$ & $10 / 148^{*}$ \\
\hline 13 & Heat shock protein 27 & gi|662841 & $7.83 / 22.4$ & $5.68 / 25.6$ & $17 / 110^{*}$ \\
\hline 14 & Heat shock protein 27 & gi|662841 & $7.83 / 22.4$ & $6.25 / 25.6$ & $17 / 110^{*}$ \\
\hline 15 & Superoxide dismutase 3 , extracellular & gi| 4507151 & $6.14 / 26.3$ & $6.32 / 28.3$ & $17 / 69^{*}$ \\
\hline 16 & Superoxide dismutase 3 , extracellular & gi| 4507151 & $6.14 / 26.3$ & $6.54 / 28.3$ & $17 / 60^{*}$ \\
\hline 17 & Osteoglycin & gi|33150528 & $5.33 / 34.2$ & $5.30 / 33.6$ & $19 / 142^{*}$ \\
\hline 18 & Osteoglycin & gi|33150528 & $5.33 / 34.2$ & $5.33 / 33.6$ & $11 / 134^{*}$ \\
\hline 19 & Skeletal muscle LIM-protein FHL1 & gi|2853224 & $8.72 / 33.8$ & $8.54 / 34.6$ & $20 / 52$ \\
\hline 20 & Alpha-actinin-2-associated LIM protein & gi|3138924 & $8.38 / 34.7$ & $8.06 / 36.7$ & $23 / 168^{*}$ \\
\hline 21 & Beta fibrinogen precursor & gi| 182430 & $8.31 / 55.5$ & $5.56 / 52.3$ & $6 / 56^{*}$ \\
\hline 22 & Fibrin beta & gi|223002 & $7.95 / 51.4$ & $6.12 / 50.1$ & $12 / 112^{*}$ \\
\hline 23 & Similar to human albumin & gi|763431 & $5.69 / 53.4$ & $5.68 / 58.3$ & $17 / 55$ \\
\hline 24 & Serum albumin & gi|55669910 & $5.57 / 67.2$ & $5.83 / 70.2$ & $30 / 162$ \\
\hline 25 & Serum albumin & gi|55669910 & $5.57 / 67.2$ & $5.84 / 70.2$ & $52 / 259$ \\
\hline 26 & Transferrin & gi|37747855 & $6.97 / 79.3$ & $7.14 / 79.1$ & $14 / 270^{*}$ \\
\hline
\end{tabular}

pl/MM, Isoelectric point/molecular mass; NCBI, National Center for Biotechnology Information. *Verification by tandem mass spectrophotometry (matrixassisted laser desorption/ionization time-of-flight/time-of-flight mass spectrometry).

Moreover, the activity of cyanide-sensitive isozymes SOD $(\mathrm{Cu} / \mathrm{Zn}$-SOD plus EC-SOD) was significantly decreased in the TAD group compared with that in the NA group $(5.69$ $\pm 0.29 \mathrm{U} / \mathrm{mg}$ vs $3.32 \pm 0.21 \mathrm{U} / \mathrm{mg}$, respectively; $P<$ .001) (Figure 5, C).

\section{Discussion}

In this study, we applied 2-DE and MS techniques to obtain protein expression profiles of the ascending aorta media from patients with TAD and normal controls. We found a total of 126 differentially expressed proteins between these 2 groups, of which 26 were identified by MS. Our results indicate that protein profiles of aortic media were significantly altered in TAD, which may contribute to the pathogenesis of the disease.

Oxidative stress plays a key role in the pathogenesis of vascular diseases. ${ }^{18}$ EC-SOD is a major form of SOD in the vessel wall and represents an important enzymatic antioxidant defense system. ${ }^{15}$ Decreased EC-SOD expression has been found to be associated with increased vascular oxidative stress. ${ }^{18}$ We found that EC-SOD expression was markedly reduced in the media samples from patients with TAD in this proteomic study (Figure 2, spots 15 and 16). Therefore, we selected this protein for further validation studies.

We examined EC-SOD protein expression in aortic media tissues by Western blotting and confirmed its lower expression in TAD samples (Figure 4). This finding was supported in additional functional assays. We showed that total SOD activity and $\mathrm{Cu} / \mathrm{Zn}$-SOD activities decreased markedly in TAD samples compared with that in normal controls (Figure 5, C). In addition, the MDA level, an indicator of lipid peroxidation, ${ }^{16}$ was increased significantly in TAD tissues (Figure 5, A). Our results indicate that oxidative stress is significantly increased in the aortic wall in patients with TAD. The data suggest that increased oxidative stress may be an important contributing factor in the pathogenesis of TAD. However, we cannot rule out at this time that the observed EC-SOC expression change is partially due to the inflammatory reaction in the TAD tissue. It is equally possible that the aorta in patients with TAD reacts poorly to existing oxidative stress because of the decreased expression of free radical scavengers, such as SOD, which may eventually lead to 

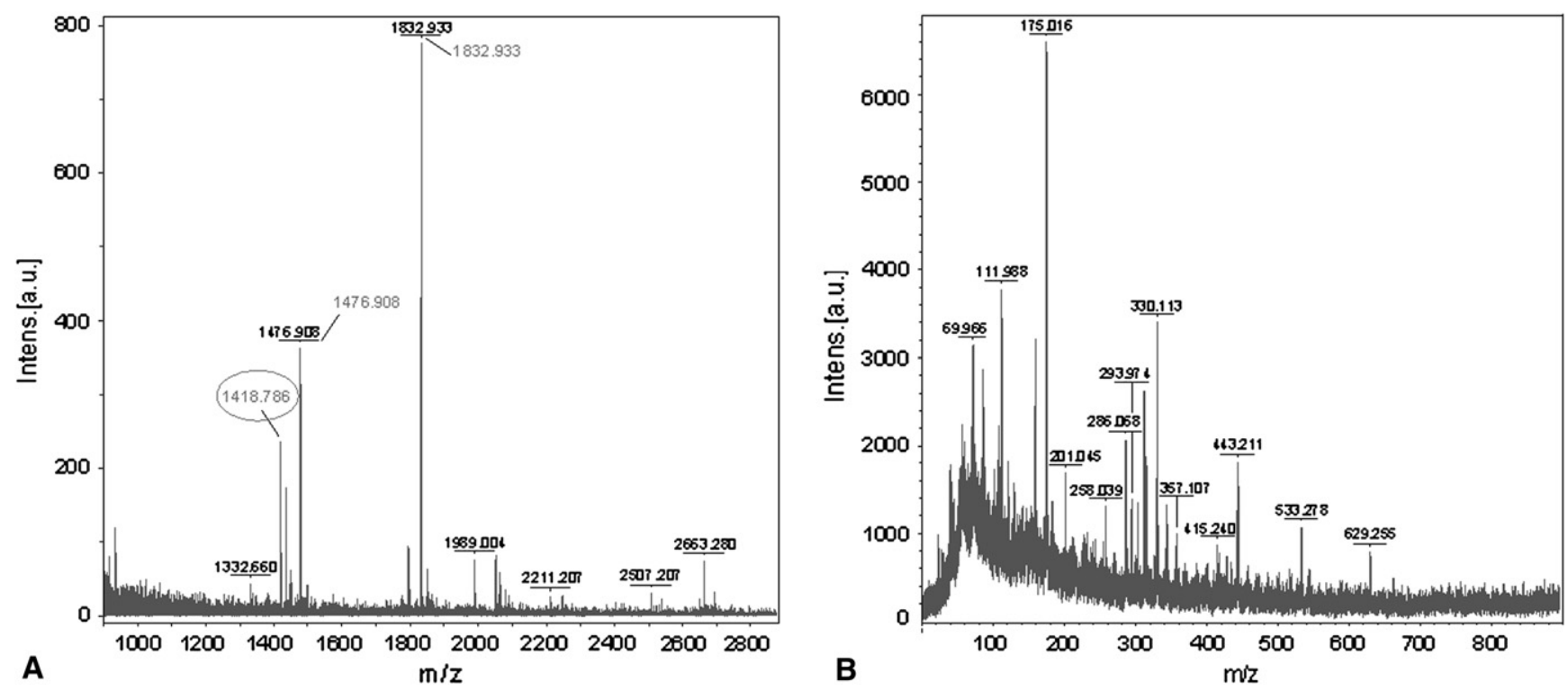

Figure 3. Peptide mass fingerprinting and tandem mass spectrophotometry spectrum of spot 15. Peptide mass fingerprinting spectrum of spot 15 by matrix-assisted laser desorption/ionization time-of-flight-MS (A). Three peptides (red) were selected for tandem mass spectrophotometry identification. Tandem mass spectrophotometry spectrum of spot 15 (B) was from $1418 \mathrm{~m} / \mathrm{z}$ (A, gray circle). Spot 15 was identified to be EC-SOD.

detrimental changes in its structure. These possibilities need to be tested in future experiments.

In addition to EC-SOD, we found other proteins that were differentially expressed between the TAD and NA groups. Among them, destrin (spot 1) is a member of the actin depo-
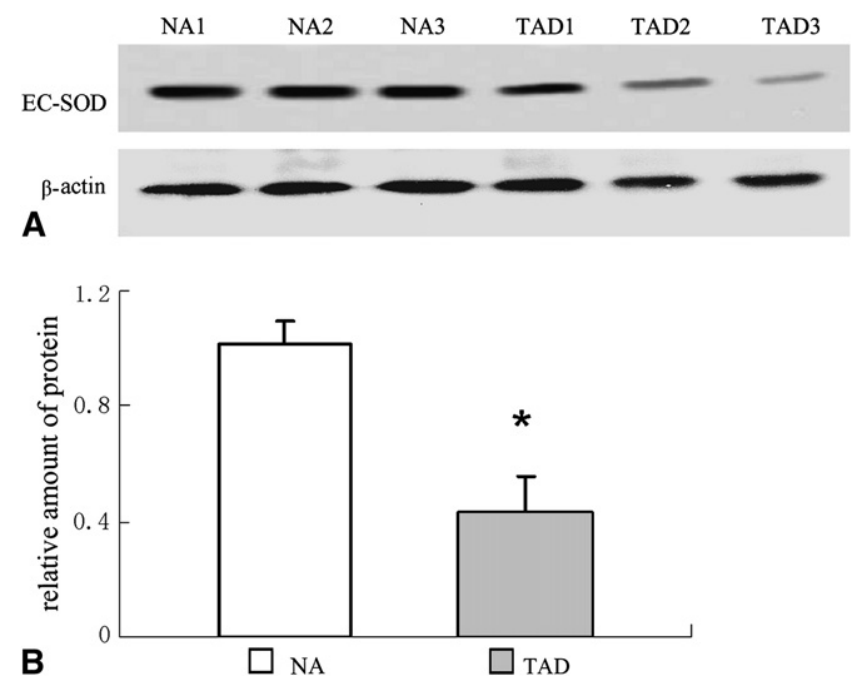

Figure 4. Western blotting verification for EC-SOD protein expression. EC-SOD and the internal control protein (beta-actin) were detected in aortic samples from the NA and TAD groups (A). Quantitative analysis of EC-SOD expression in $\operatorname{TAD}(n=8)$ and $\mathrm{NA}(\mathrm{n}=$ 6) groups (B). * $P<.05$. EC-SOD, Extracellular superoxide dismutase; $N A$, normal thoracic aorta; $T A D$, thoracic aortic dissection. lymerizing factor family and regulates actin cytoskeleton in various eukaryotes. ${ }^{19}$ Smooth muscle 22 -alpha, represented by spots 2 to 5 for its isoforms or modifications of the protein, is a $\mathrm{SMC}$-specific actin binding protein that is considered as an earliest contractile marker of differentiated SMCs. ${ }^{20}$ Feil and colleagues ${ }^{21}$ showed that smooth muscle 22 alpha-modulated vascular SMCs phenotype during vascular remodeling. Skeletal muscle LIM-protein FHL1 (spot 19) and ALP (spot 20) are involved in cytoskeletal integrity ${ }^{22}$ and reorganization. ${ }^{23}$ The altered expression of these cytoskeletal proteins in the aortic media of patients with TAD indicates that cytoskeletal reorganization may be impaired in the aorta, suggesting a possible mechanism of defective aortic remodeling in the disease.

We also found 2 isoforms of HSP27 (spots 13 and 14) in the aortic media of patients with TAD. These proteins are similar to 2 distinct HSP27 isoforms identified in human venous media by McGregor and colleagues. ${ }^{10}$ HSP27 is likely to play a role in the actin filament remodeling during SMC migration and contractions. ${ }^{24}$ It has been suggested that HSP27 increases the resistance against oxidative stress-induced actin fragmentation. ${ }^{25}$ Therefore, HSP27 may play a role in the remodeling process of TAD, partially by regulating SMC functions.

Another interesting finding was the decreased osteoglycin protein (spots 17 and 18) in patients with TAD. Previous studies on osteoglycin expression in rat SMCs and carotid arteries, as well as human coronary arteries, have suggested that this protein is a new marker for differentiated SMCs 

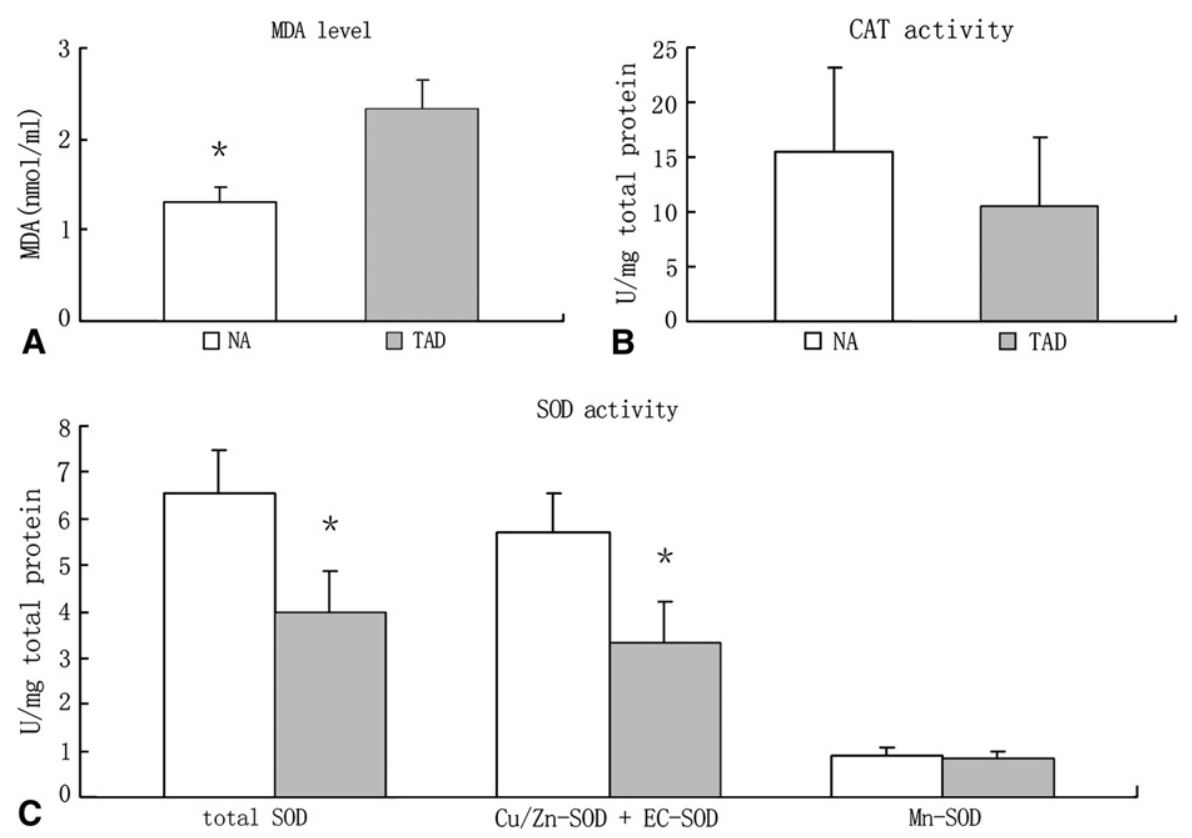

Figure 5. MDA levels, catalase activity, and SOD activity in aortic samples. Increased MDA in the TAD group compared with that in the NA group (A). Catalase activity was lower in the TAD group than in the NA group, but the difference was not statistically significant (B). Total SOD activity and activities of cyanide-sensitive SOD (Cu/Zn-SOD plus EC-SOD) were also decreased in the TAD group compared with the NA group (C). ${ }^{*} P<.05$. MDA, Malondialdehyde; $N A$, normal thoracic aorta; $T A D$, thoracic aortic dissection; EC-SOD, extracellular superoxide dismutase; Mn-SOD, manganese-superoxide dismutase; SOD, superoxide dismutase. and may be an essential component of the normal vascular matrix. ${ }^{26}$ The decreased osteoglycin expression in patients with TAD suggests that SMC phenotypic change and vascular matrix remodeling may occur in the aortic media of TAD.

\section{Conclusions}

Our proteomic analysis of the aortic media from the TAD and NA groups identified a number of differentially expressed proteins. In particular, we found expression pattern changes in EC-SOD, osteoglycin, and some cytoskeletal proteins in tissues from patients with TAD. These new findings suggest that increased oxidative stress and impaired vessel wall remodeling may be possible molecular mechanisms in the pathogenesis of TAD. We recognize that the patient sample size in this study was small and that protein spots identified by computer-based statistical algorithm need to be verified experimentally. At this time, it is unclear whether the protein expression changes observed are the cause or effect of the dissection. Thus, additional mechanistic studies are needed to define the role of the identified proteins in TAD. Our results should encourage further characterization of the differentially expressed proteins, which may lead to new hypotheses. Together, a better understanding of the molecular mechanisms underlying TAD should help to design more effective strategies to diagnose and treat this life-threatening disease.

The use of the facilities of the Research Center for Proteome Analysis of the Shanghai Institute of Biochemistry is gratefully acknowledged. We thank Dr Jibin Xu (Department of Thoracic Surgery, Changhai Hospital) for providing aortic samples and Dr Matthew Eagleton (Department of
Vascular Surgery, Cleveland Clinic) for critical reading of this article.

\section{References}

1. Nienaber CA, Eagle KA. Aortic dissection: new frontiers in diagnosis and management. part I: from etiology to diagnostic strategies. Circulation. 2003;108:628-35.

2. Mészáros I, Mórocz J, Szlávi J, Schmidt J, Tornóci L, Nagy L, et al. Epidemiology and clinicopathology of aortic dissection. Chest. 2000; 117:1271-8

3. Guo D, Hasham S, Kuang SQ, Vaughan CJ, Boerwinkle E, Chen H, et al. Familial thoracic aortic aneurysms and dissections: genetic heterogeneity with a major locus mapping to 5q13-14. Circulation. 2001;103:2461-8

4. Blackstock WP, Weir MP. Proteomics: quantitative and physical mapping of cellular proteins. Trends Biotechnol. 1999;17:121-7.

5. Alaiya A, Al-Mohanna M, Linder S. Clinical cancer proteomics: promises and pitfalls. J Proteome Res. 2005;4:1213-22.

6. Matt P, Carrel T, White M, Lefkovits I, VanEyk J. Proteomics in cardiovascular surgery. J Thorac Cardiovasc Surg. 2007;133:210-4.

7. Duran MC, Mas S, Martin-Ventura JL, Meilhac O, Michel JB, Gallego-Delgado J, et al. Proteomic analysis of human vessels: application to atherosclerotic plaques. Proteomics. 2003;3:973-8.

8. You SA, Archacki SR, Angheloiu G, Moravec CS, Rao S, Kinter M, et al. Proteomic approach to coronary atherosclerosis shows ferritin light chain as a significant marker: evidence consistent with iron hypothesis in atherosclerosis. Physiol Genomics. 2003;13:25-30.

9. Dupont A, Corseaux D, Dekeyzer O, Drobecq H, Guihot AL, Susen S, et al. The proteome and secretome of human arterial smooth muscle cells. Proteomics. 2005;5:585-96.

10. McGregor E, Kempster L, Wait R, Welson SY, Gosling M, Dunn MJ, et al. Identification and mapping of human saphenous vein medial smooth muscle proteins by two-dimensional polyacrylamide gel electrophoresis. Proteomics. 2001;1:1405-14.

11. Weekes J, Wheeler CH, Yan JX, Weil J, Eschenhagen T, Scholtysik G, et al. Bovine dilated cardiomyopathy: proteomic analysis of an animal model of human dilated cardiomyopathy. Electrophoresis. 1999;20: 898-906. 
12. Bradford MM. A rapid and sensitive method for the quantitation of microgram quantities of protein utilizing the principle of protein-dye binding. Anal Biochem. 1976;72:248-54.

13. Yu LR, Zeng R, Shao XX, Wang N, Xu YH, Xia QC. Identification of differentially expressed proteins between human hepatoma and normal liver cell lines by two-dimensional electrophoresis and liquid chromatography-ion trap mass spectrometry. Electrophoresis. 2000; 21:3058-68.

14. Jin X, Li X, Wang LS, Shi JZ, Zheng Y, Chen WL, et al. Differential protein expression in hypertrophic heart with and without hypertension in spontaneously hypertensive rats. Proteomics. 2006;6:1948-56.

15. Stralin P, Karlsson K, Johansson BO, Marklund SL. The interstitium of the human arterial wall contains very large amounts of extracellular superoxide dismutase. Arterioscler Thromb Vasc Biol. 1995;15:2032-6.

16. Ohkawa H, Ohishi N, Yagi K. Assay for lipid peroxides in animal tissues by thiobarbituric acid reaction. Anal Biochem. 1979;95:351-8.

17. Yasmineh WG, Kaur TP, Blazar BR, Theologides A. Serum catalase as marker of graft-versus-host disease in allogenic bone marrow transplant recipients: pilot study. Clin Chem. 1995;41:1574-80.

18. Landmesser U, Spiekermann S. Vascular oxidative stress and endothelial dysfunction in patients with chronic heart failure: role of xanthine-oxidase and extracellular superoxide dismutase. Circulation. 2002;106:3073-8.

19. Yahara I, Aizawa H, Moriyama K, Iida K, Yonezawa N, Nishida E, et al. A role of cofilin/destrin in reorganization of actin cytoskeleton in response to stresses and cell stimuli. Cell Struct Funct. 1996;21: $421-4$.

20. Gimona M, Sparrow MP, Strasser P, Herzog M, Small JV. Calponin and SM22 isoforms in avian and mammalian smooth muscle. Absence of phosphorylation in vivo. Eur J Biochem. 1992;205:1067-75.

21. Feil S, Hofmann F, Feil R. SM22 alpha modulates vascular smooth muscle cell phenotype during atherogenesis. Circ Res. 2004;94:863-5.

22. McGrath MJ, Mitchell CA, Coghill ID, Robinson PA, Brown S. Skeletal muscle LIM protein 1 (SLIM1/FHL1) induces $\alpha 5 \beta 1$-integrin-dependent myocyte elongation. Am J Physiol Cell Physiol. 2003;285:1513-26.

23. Kiwon JO, Rutten B, Bunn RC, Bredt DS. Actinin-associated LIM protein-deficient mice maintain normal development and structure of skeletal muscle. Mol Cell Biol. 2001;21:1682-7.

24. An SS, Fabry B, Mellema M, Bursac P, Gerthoffer WT, Kayyali US, et al. Role of heat shock protein 27 in cytoskeletal remodeling of the airway smooth muscle cell. J Appl Physiol. 2004;96:1701-13.

25. McGregor E, Kempster L, Wait R, Gosling M, Dunn MJ, Powell JT. F-actin capping (CapZ) and other contractile saphenous vein smooth muscle proteins are altered by hemodynamic stress: a proteomic approach. Mol Cell Proteomics. 2004;3:115-24.

26. Shanahan CM, Cary NR, Osbourn LK, Weissberg PL. Identification of osteoglycin as a component of the vascular matrix: differential expression by vascular smooth muscle cells during neointima formation and in atherosclerotic plaques. Arterioscler Thromb Vasc Biol. 1997;17: 2437-47. 


\section{Appendix E1}

The first dimension immobilized pH gradients Dalt (IPG-Dalt) 2-dimensional gel electrophoresis was run on an IPGphor isoelectric focusing (IEF) system. IEF was performed using 130-mm, immobilized, nonlinear pH gradient strips (IPG DryStrips; GE Healthcare, AmershanBiosciences, Piscataway, NJ) of $\mathrm{pH} 3$ to 10 . A total protein load of $100 \mu \mathrm{g}$ per IPG DryStrip was mixed with a rehydration solution containing $8 \mathrm{~mol} / \mathrm{L}$ urea, $2 \%$ CHAPS, $0.5 \%$ IPG buffer, $\mathrm{pH} 3-10 \mathrm{~L}, 18 \mathrm{mmol} / \mathrm{L}$ dithiothreitol (DTT), and a trace of bromophenol blue, to a total volume of $250 \mu \mathrm{L}$, and rehydrated overnight in a re-swelling tray. After rehydration for 12 hours, IEF was conducted automatically at low voltages (500$1000 \mathrm{~V}$ ) during the first 2 hours and then continued with a maximum setting of $8000 \mathrm{~V}$ to reach a total of $40 \mathrm{kVh}$ for analytic runs or 65 to 70 $\mathrm{kVh}$ for preparative runs at $20^{\circ} \mathrm{C}$. After IEF separation, the strips were equilibrated in $6 \mathrm{~mol} / \mathrm{L}$ urea containing 30\% (v/v) glycerol, $2 \%$ (w/v) sodium dodecylsulfate, and $0.01 \%(\mathrm{w} / \mathrm{v})$ bromphenol blue, with the addition of $1 \%(\mathrm{w} / \mathrm{v})$ DTT for 15 minutes, followed by the same buffer without DTT but with the addition of $2.5 \%$ (w/v) iodoacetamide for 15 minutes. Sodium dodecylsulfate-polyacrylamide gel electrophoresis was performed using 1-mm-thick, $12 \%$ T, 2.6\% C separating polyacrylamide gels without a stacking gel using the Hoefer SE 600 (Amersham). The second dimension was carried out at a constant current of $10 \mathrm{~mA} / \mathrm{gel}$ for 15 minutes and then switched to $30 \mathrm{~mA} / \mathrm{gel}$ until the bromphenol dye front had reached the bottom of the gels. After electrophoresis, analytic 2-dimensional gels were fixed for a minimum of 1 hour in a methanol:acetic acid:water solution $(4: 1: 5 \mathrm{v} / \mathrm{v} / \mathrm{v})$. Analytic 2-dimensional protein profiles were visualized by silver staining using the OWL Silver Staining Kit (Insight Biotechnology Ltd, Wembley, UK), and preparative 2-dimensional gels were stained using Coomassie Brilliant Blue R-350 stain for subsequent mass spectrometry analysis. 
TABLE E1. Clinical characteristics of groups with normal thoracic arteries and thoracic aortic dissection

\begin{tabular}{|c|c|c|c|c|}
\hline & $N A^{*}(n=6)$ & $\operatorname{TAD}^{*}(\mathrm{n}=8)$ & $N A \dagger(n=10)$ & $\operatorname{TAD} \dagger(n=15)$ \\
\hline Age (y) & $39.5 \pm 7.2$ & $47.5 \pm 6.9$ & $40.9 \pm 6.7$ & $47.4 \pm 9.2$ \\
\hline Male/female & $6 / 0$ & $8 / 0$ & $13 / 2$ & $9 / 1$ \\
\hline Maximal diameter $(\mathrm{cm})$ & $2.48 \pm 0.29$ & $5.56 \pm 1.17$ & $2.36 \pm 0.29$ & $5.55 \pm 1.11$ \\
\hline Atherosclerosis & $2(33.3 \%)$ & $7(87.5 \%)$ & $3(33.3 \%)$ & $14(93.3 \%)$ \\
\hline Hypertension & $0(0.0 \%)$ & $7(87.5 \%)$ & $0(0.0 \%)$ & $13(86.6 \%)$ \\
\hline Bicuspid aortic valve & $0(0.0 \%)$ & $0(0.0 \%)$ & $0(0.0 \%)$ & $0(0.0 \%)$ \\
\hline Marfan syndrome & $0(0.0 \%)$ & $0(0.0 \%)$ & $0(0.0 \%)$ & $0(0.0 \%)$ \\
\hline DeBakey type I aortic dissection & - & $8(100 \%)$ & - & $15(100 \%)$ \\
\hline
\end{tabular}

$N A$, Normal thoracic aorta; $T A D$, thoracic aortic dissection. *Sample groups for proteomic analysis. $†$ Sample groups for oxidative stress assay (including the samples in *groups). 
TABLE E2. Protein sequences identified by matrix-assisted laser desorption/ionization time-of-flight and time-of-flight mass spectrometry

\begin{tabular}{|c|c|c|c|c|}
\hline $\mathbf{N}$ & Protein identity & Peptide matches & Sequences & Sequence coverage $(\%)$ \\
\hline 1 & Destrin & 2 & $\begin{array}{l}\text { R.YALYDASFETK.E } \\
\text { K.HFVGMLPEKDCR.Y }\end{array}$ & 17 \\
\hline 3 & Smooth muscle 22-alpha/transgelin & 3 & $\begin{array}{l}\text { R.LGFQVWLK.N } \\
\text { K.TDMFOTVDLFEGK.D } \\
\text { R.LVEWIIVQCGPDVGRPDR.G }\end{array}$ & 19 \\
\hline 11 & Actin, alpha 2, smooth muscle, aorta & 3 & $\begin{array}{l}\text { R.AVFPSIVGRPR.H } \\
\text { K.IWHHSFYNELR.V } \\
\text { R.VAPEEHPTLLTEAPLNPK.A }\end{array}$ & 26 \\
\hline 13 & Heat shock protein 27 & 3 & $\begin{array}{l}\text { R.RVPFSLLR.G } \\
\text { R.LFDQAFGLPR.L } \\
\text { R.VSLDVNHFAPDELTVK.T }\end{array}$ & 17 \\
\hline 15 & Superoxide dismutase 3 , extracellular & 3 & $\begin{array}{l}\text { K.VTEIWOEVMQR.R } \\
\text { R.AGLAASLAGPHSIVGR.A } \\
\text { R.LACCVVGVCGPGLWER.0 }\end{array}$ & 17 \\
\hline 17 & Osteoglycin & 4 & $\begin{array}{l}\text { K.DFADIPNLR.R } \\
\text { R.IEEIRLEGNPIVLGK.H } \\
\text { K.LSLLEELSLAENQLLK.L } \\
\text { R.RLDFTGNLIEDIEDGTFSK.L }\end{array}$ & 19 \\
\hline 20 & Alpha-actinin-2-associated LIM protein & 4 & $\begin{array}{l}\text { R.LSGGIDFNQPLVITR.I } \\
\text { K.INLESEPQEFKPIGTAHNR.R } \\
\text { R.GLIPSSPQNEPTASVPPESDVYR.M } \\
\text { K.GYFFIEGELYCETHAR.A }\end{array}$ & 23 \\
\hline
\end{tabular}

